\title{
CORAK FIQH DIACEH PADAMASAKERAJAAN \\ (KAJIAN ATAS NASKAH AL-HADIAL-MUHTAJF1SYARAH AL-MINHAJ KARYAIMAMABIQASIM IMAMUDDIN ABDUL KARIM AR-RAFI'I) \\ Fiqh Complexion in Aceh in the Kingdom Era \\ (Review of the Al-Hadi Al-Muhtaj Fi Syarah Al-Minhaj Manuscript the work of Abi Qasim Imamuddin Abdul Karim Ar-Rafi'i)
}

\author{
Oleh: Mursyid* \\ *Dosen Ar-Raniri Banda Aceh \\ E-mail: Mursyidmandar@yahoo.co.id
}

\begin{abstract}
Abstrak
Penelitian ini difokuskan pada penelitian tentang corak fiqh diAceh pada masa kerajaan dengan meneliti naskah Al-Hadi Al-Muhtaj fi Syarah al-Minhaj kary a Imam Abi Qasim Imamuddin Abdul Karim Ar-Rafi'i. Permasalahan yang ditetliti dalam penelitian ini adalah Bagaimana deskripsi naskah, isi pembahasan dan corak figh naskah Al-Hadi Al-Muhtaj fi Syarah al-Minhaj karya Imam Abi Qasim Imamuddin Abdul Karim Ar-Rafi 'i? Untuk membahas ketiga hal tersebut, digunakan dua metode, yaitu; metode penelitian kodikologi dan filologi. Untuk analisis isi naskah, digunakan metode penelitian fiqh. Dari hasil penelitian ditemukan bahwa naskah Al-Hadi Al-Muhtaj fi Syarah al-Minhaj karya Imam Abi Qasim Imamuddin Abdul Karim Ar-Rafi 'i menggunakan bahasa Arab dengan aksara Arab yang berbentuk prosa. Kondisi naskah secara umum baik dan isi teks dapat dibaca dengan baik. Bahan naskah ini adalah kertas Eropa yang dapat dilihat pada cap kertas yang diperkirakan sekitar tahun 1610 M. Naskah ini berisi tentangpersoalan fiqh yang bercorak mazhab Syafi'i yang dapat dijadikan salah satu data ilmiah untuk membuktikan bahwa corak fiqh di Aceh pada masa kerajaan adalah fiqh mazhab syafi'i.
\end{abstract}

Kata Kunci: Corak fiqh, Masa Kerajaan, Aceh, Naskah, Ar-Rafi'i

\section{Abstract}

This research focused on patterns of fiqh in Aceh during the kingdom by examined the manuscript of AlHadi Al-Muhtaj fi Sharh al-Minhaj, the works of Abi Qasim Imamuddin Abdul Karim Al-Rafi'i. Problems analyzed in this study is how the description of the manuscript, the contents of the discussion andpattern of manuscript fiqh al-Hadi al-Muhtajfi Sharhal-Minhaj works of Imam Abi Qasim Imamuddin Abdul KarimAlRafi'i. To discuss those three things, applied two methods, they are: kodikologi's and philology methods. To analyze the content of the script, it is applied fiqh analysis method. From this research found that the manuscript ofAl-HadiAl-Muhtaj fi Sharh al-Minhaj Imamuddin the works of Imam AbuQasim Abdul Karim Al-Rafi $T$ with Arabic script in theform of prose. The conditions of the script were generally good and content of the text can be readproperly. This manuscript material is an European paper that can be seen in the stamp paper which is predicted around the year 1610 AD This manuscript contains about fiqh issues figured with school of Syafii that can be taken as one of the scientific data to prove that the figure offiqh in Aceh in the era of kingdom is the fiqh with school of Syafii.

KeyWords: Pattern of fiqh, era of Aceh kingdom, manuscripts,Ar-Rafi'i

\section{PENDAHULUAN}

$\mathrm{F}$ iqh" dalam konteks keindonesiaan, dalam sejarahnya, bisa dikatakan mengalami perkembangan yang sangat signifikan. Pada masamasa awal, fuqahd' yang ada di nusantara baru sampai padatataran mengajarkan dan mengaplikasikan fiqh-fiqh karya ulama-ulama yang ada di kawasan Timur Tengah (basis-basis awal Islam). Hal ini kemudian yang menjadikan masyarakat Indonesia menganut satu mazhab, yaitu mazhab yang dianut oleh fuqahd' yang membawa Islam ke Indonesia. ${ }^{2}$

Figh secara etimologi, berasal dari kata Lihat, Al-Tahir Ahmad al-Zawy, Tartib al-Qamiis al-Muhith, Juz. Ill; (Cet. Ill; Beirut: Dar al-Fikr, t,th), h. 513.

Kenyataan inilah yang menjadikan figh yang berkembang di Indonesia, umumnya, merupakan karya tokoh-tokoh pada masa kejayaan Islam yang berlangsung sekitar 250 tahun, yaitu sejak abad ke-2 H sampai 4 H. Sehingga diwamai oleh kepribadian Arab (Arab oriented). Lihat Marzuki Wahid dan Rumadi, Figh Madhhab Negara; Kritik atas Politik Hukum Islam di Indonesia (Cet. I; Yogyakarta: LKIS, 2001). h. 129. 
Gambaran fiqh yang berkembang di Indonesia ada masa ini tercermin dalam tulisan Hasbi Ash:ddiqi yang mengemukakan bahwa bahwa Fiqh ang berkembang dalam masyarakat kita sekarang agiannya adalah fiqh Hijaz yaitu fiqh yang :'^entuk atas dasar adat istiadat yang berlaku di Hijaz, v.sdfiqh Mishry yaitu fiqh yang terbentuk atas dasar aaat istiadat dan kebiasaan Mesir ataufiqh Hindi yaitu "-;h yang terbentuk atas urf dan adat istiadat yang " =:laku di India. Selama ini kita belum menunjukkan - tTiampuan untuk berijtihdd mewujudkan fiqh yang rsuai dengan kepribadian Indonesia, karena itu - adang-kadang kita paksakan fiqh Hijaz atau fiqh Mishry atau fiqh Irak berlaku di Indonesia atas dasar akiid. ${ }^{3}$

Tulisan Hasby di atas, melukiskan bahwa ada -;ian-bagian fiqh kaum muslimin Indonesia yang - aasarkan pada urf Timur Tengah yang tidak sesuai :engan rasa kesadaran hukum masyarakat Indonesia ang melembaga dalam hukum adat. Atas dasar itulah -:a bagian-bagian tertentu dari fiqh yang kurang endapat sambutan hangat dari masyarakat Indonea. karena dianggap sesuai dengan kepribadian leluarga. ${ }^{4}$

Perkembangan fiqh secara umum di atas, tentu aja tidak akan jauh berbeda dengan perkembangan : h yang ada di Aceh pada masa lampau. Hal ini dapat : hat pada tokoh-tokoh fiqh ketika Aceh masih dalam - cntuk kerajaan. Seperti; Nur Al-Din Al-Raniry (W. '.068 H/1658 M) ${ }^{5}$ dan Syeikh Abdurrauf Singkel (1024

$615 \mathrm{M})^{6}$ Mereka adalah ulama yang merupakan :'enganut mazhab syafi'i.

Dari gambaran sepintas perkembangan fiqh di Nusantara dan khususnya di Aceh di atas, tentu - enimbulkan pertanyaan mendasar tentang bagaimana corak perkembangan fiqh di Aceh pada masa lampau. Untuk menjawab pertanyaan mendasar ini, maka diperlukan kajian atas manuskrip kitab-kitab fiqh yang dipakai di Aceh. Salah satu kitab tersebut adalah Al-Hadi Al-Muhtaj fi Syarah al-Minhaj karya Imam Abi Qasim Imamuddin Abdul Karim ArRafi'i. Naskah ini penulis temukan di Kabupaten Aceh Besar, Provinsi Nanggroe Aceh Darussalam. Naskah ini merupakan dokumentasi pribadi masyarakat yang belum teridentifikasi dan terdaftar pada perpustakaan ataupun museum terkait. Atas dasar inilah, penelitian atas naskah Al-Hadi AlMuhtaj fi Syarah al-Minhaj karya Imam Abi Qasim Imamuddin Abdul Karim Ar-Rafi'i ini menarik untuk dilakukan.

Dari latar belakang di atas dapat dirumuskan beberapa masalah yang diteliti dalam penelitian ini, yaitu: (1) bagaimana deskripsi n\&skah Al-Hadi AlMuhtaj fi Syarah al-Minhaj karya Imam Abi Qasim Imamuddin Abdul Karim Ar-Rafi'i?, (2) apa saja isi naskah Al-Hadi Al-Muhtaj fi Syarah alMinhaj karya Imam Abi Qasim Imamuddin Abdul Karim Ar-Rafi'i?, (3) bagaimana corak fiqh naskah Al-Hadi Al-Muhtaj fi Syarah al-Minhaj karya Imam Abi Qasim Imamuddin Abdul Karim ArRafi'i?

Tujuan penelitian naskah Al-Hadi Al-Muhtaj fi Syarah al-Minhaj karya Imam Abi Qasim Imamuddin Abdul Karim Ar-Rafi'i ini paling tidak adatiga hal yaitu: (1) untuk menyajikan deskripsi naskah Al-Hadi AlMuhtaj fi Syarah al-Minhaj karya Imam Abi Qasim Imamuddin Abdul Karim Ar-Rafi'i, (2) Untuk meneliti naskah Al-Hadi Al-Muhtaj fi Syarah al-Minhaj karya Imam Abi Qasim Imamuddin Abdul Karim ArRafi'i dengan menggunakan pendekatan kodikologi dan

Hasbi Ash-Shiddiqy, Syari'at Islam Menjawab Tantangan Zaman (Jakarta: Bulan Bintang, 1966), h. 41-42. Kutipan ini juga dimuat dalam -ruzzaman Ash Shiddiqy, Fiqh Indonesia: Penggagas dan Gagasannya (cet. I; Yogyakarta: Pustaka Pelajar, 1997), h. 57.

Contoh yang konkrit tentang fiqh yang kurang sesuai dengan adat di Indonesia adalah tentang nasab dari vvali nikah. Bagi masyarakat "-b. penunjukan wali nikah atas dasar garis Bapak (patrinial) sangat tepat karena adat mereka memang seperti itu. tapi bagi masyarakat ": nesia, penunjukkan itu masih harus dipertahankan. Di Jawa kedudukaan ibu sama kuatnya dengan kedudukan pihak bapak, di Minangkabau -matra) masyarakatnya meniirut garis ibu, di Tapanuli menurut garis bapak. Atas dasar ini, Hazairin berpendapat bahwa untuk kasus wali di ranuli telah selaras dengan susunan masyarakatnya jika wali itu diambil dari pihak garis bapak. Namun, bagi masyarakat di Minagkabau :"unjukkan dari pihak garis ibulah yang selaras dengan susunan masyarakatnya, sedangkan di Jawa penunjukkan itu dapat dilakukan dari ;ngan garis ibu atau pun garis bapak. Lihat Huzairin, Hukum Islam dan Masyarakat (Cet. IV; Jakarta: Bulan Bintang, 1981), h. 13-14.

Nur Al-Din Al-Raniry dilahirkan di Ranir (Randir), sebuah kota pelabuhan tua di pantai Gujarat. Tahun kelahirannya tidak diketahui, akan :ipi diduga kuat ia lahir menjelang akhir abad keenan belas. Ibunya adalah seorang Melayu sedang ayahnya adalah seorang Hadhrami. .imardi Azra, Jaringan Ulama Timur Tengan dan Kepulauan Nusantara Abad XVII dan XVIII, (Cet. IV; Bandung: Mizan, 1998), hal. 169.

- Abdurrauf lahir di Aceh tahun (1024 H/1615 M) nama aslinya adalah Aminuddin Abdurrauf bin Ali al-Jawi al-Fansuri al-Singkili. Abdurrauf -gkel merupakan sosok pemikir dan ulama terkemuka, ia telah melahirkan karya-karya dalam berbagai disiplin ilmu keislaman (Islamic idies) yang merupakan kekayaan intelektual muslim Indonesia yang sangat berharga. Abdul Aziz Dahlan, et.al. Ensiklopedi Hukum Islam. id 1. Jakarta: Ikhtiar Baru Van Hoeve, 1996), h. 5 
filologi, (3) untuk mengetahui corak fiqh naskah ^4/Hadi Al-Muhtaj fi Syarah al-Minhaj karya Imam Abi Qasim Imamuddin Abdul KarimAr-Rafi'i.

Penelitian tentang corak fiqh di Aceh pada masa Kerajaan belum banyak dilakukan, terutama yang menekankan terhadap kajian naskah klasik. Namun demikian, kajian tentang perkembangan pemikiran secara umum di Aceh pada masa kerajaaan sudah ada beberapa penelitian dan buku. Di antaranya;

Azyumardi Azra yang menulis buku Jaringan Ulama Timur Tengah dan Kepulauan Nusantara Abad XVII dan XVIII, B andung; Mizan." Buku ini secara umum membahas tentang jaringan ulama nusantara yang salah satu pembahasannya juga membahas jaringan ulama di Aceh.

Abdul Hadi W.M., menulis buku Hamzah Fansuri: Risalah Tasawuf dan Puisi-puisinya, Bandung: Mizan. Buku ini membahas tentang risalah tasawuf Hamzah Fansuri yang merupakan ulama Aceh pada masa kerajaan.

Ahmad Daudy yang menulis buku Syekh Nuruddin Ar-Raniry, Jakarta: Bulan Bintang. Buku ini merupakan kajian historis terhadap Syekh Nuruddin Ar-Raniry sebagai salah satu ulama yang sangat berpengaruh pada masa kerajaan Aceh.

Oman Fathurrahman menulis buku Menyoal Wahdatul Wujud: Kasus Abdurrauf Singkel di Aceh Abad VII, Jakarta: Mizan. Buku ini mengkaji tentang paham sufistik yang dikembangkan oleh Abdurrauf Singkel di Aceh pada masa kerajaan.

Dari beberapa telaah pustaka yang dikemukakan di atas, dapat ditegaskan bahwa penelitian ini adalah penelitian yang belum dilakukan oleh para peneliti/ penulis sebelumnya.

Penelitian ini merupakan studi kepustakaan \{library research) yang dilakukan dengan cara melacak sumber terkait di dokumentasi pribadi masyarakat. Dari pelacakan naskah yang dikehendaki yakni naskah
Al-Hadi Al-Muhtaj fi Syarah al-Minhaj karya Imam Abi Qasim Imamuddin Abdul Karim Ar-Rafi' i, kemudian dilakukan inventarisasi dan deskripsi naskah.

Metode yang digunakan dalam makalah ini, terdiri atas dua, yaitu; Pertama, metode penelitian kodikologi' dan filologi. Metode Penelitian ini digunakan dengan penelitian berdasarkan penelusuran naskah melalui berbagai katalog untuk kemudian menyajikan teks ${ }^{8}$. Untuk analisis isi naskah, digunakan metode penelitian fiqh'. Metode ini dipilih karena naskah Al-Hadi AlMuhtaj fi Syarah al-Minhaj karya Imam Abi Qasim Imamuddin Abdul Karim Ar-Rafi'i ini berisi tentang persoalan fiqh.

\section{PEMBAHASAN}

\section{Inventarisasi Naskah}

Naskah yang berjudul Al-Hadi Al-Muhtaj $f i$ Syarah al-Minhaj ini merupakan koleksi pribadi. Naskah ini ditemukan dalam penelusuran penulis di desa Lambirah Kecamatan Indrapuri, Kabupaten Aceh Besar, Provinsi Nanggroe Aceh Darussalam. Naskah ini merupakan dokumentasi pribadi Tgk. $\mathrm{H}$. Adnan Hasyim. Naskah ini belum teridentifikasi dan terdaftar pada perpustakaan ataupun museum terkait.

Mengenai pengarang naskah ini tidak banyak informasi yang bisa diperoleh karena naskah ini belum teridentifikasi dan terdaftar pada perpustakaan ataupun museum yang ada di Aceh. Pada halaman awal dari naskah ini, ditemukan bahwa naskah ini merupakan karya Imam Abi Qasim Imamuddin Abdul Karim Ar-Rafi'i. Dalam penelusuran penulis pada e-books \{Maktabah al-Syamilah), ditemukan bahwa Imam Abi Qasim Imamuddin Abdul Karim Ar-Rafi'i adalah fuqaha' yang bermazhab syafi'i, wafat pada tahun $623 \mathrm{H}^{10}$

\section{Deskripsi Naskah}

Judul naskah ini adalah Al-Hadi Al-Muhtaj $f i$ Syarah al-Minhaj yang merupakan hasil karya dari Imam Abi Qasim Imamuddin Abdul KarimAr-Rafi'i. Naskah ini menggunakan bahasa Arab dengan aksara Arab yang berbentuk prosa.

Penelitian kodikologi mempelajari seluk beluk semua aspek naskah, seperti bahan, umur, tempat penulisan dan perkiraan penulisan naskah, Titik Pudjiastuti. 2006. Naskah dan Studi Naskah, Bogor: Akademia. h. 35.

Mu'jizah. 2005. Martabat Tujuh: Edisi Teks dan Pemaknaan Tanda serta Simbol, Jakarta: Djambatan. h. 11.

Yusuf Qadhrawi mendefenisikan Figh sebagai ilmu yang berkaitan dengan pet-istimbdpan hukum-hukum syari 'at amaliyah (praktis) dari dalildalilnya yang terperinci. Lihat Yusuf Qardhawi. 1993. Madkhal li Dirdsat al-Syaridt al-Islamiyah, Beirut: Muassasat al-Risalah, h, 21.

CD Room, Maktabah Al-Syamilah. 
Kondisi naskah secara umum baik dan isi teks dapat dibaca dengan baik. Hanya saja pada pertengahan naskah dimakan tinta. Kondisi fisik naskah dapat digambarkan bahwajilidan naskah masih asli yang terbuat dari kulit binatang berwarna coklat. Naskah diletakkan dalam jilid tebal yang tidak melekat dengan naskah. Bahan naskah ini adalah kertas Eropa. Ukuran kertasnya adalah 22 x $16 \mathrm{~cm}$ sedangkan ukuran teksnya 15 x $10 \mathrm{~cm}$. Tentang cap kertas ditemukan watermark yang bergambar bulan sabit bersusun tiga (Edward Heawood, no. 863). Diperkirakan sekitar tahun 1610 M." Dari bentuk kertasnya pun dapat dipastikan bahwa naskah menggunakan kertas Eropa.

Naskah ini berjumlah 420 alaman. Halaman yang kosong berjumlah 16 halaman (2 halaman di awal naskah, 11 halaman di tengah dan 3 halaman di akhir naskah). Jenis khat yang digunakan adalah khat naskhi dengan menggunakan tinta hitam serta rubrukasi menggunakan tinta merah. Pada catchword naskah ditemukan bahwa di setiap halaman terdapat alihan.

Naskah ini berisi tentang bahasan fiqh yang mencakup aturan-aturan rinci mengenai aspek ibadah, munakahat, mu 'amalah dan jinayah. Pembahasannya didasarkan pada pendapat-pendapat dalam kitab-kitab fikih bermazhab Syafi'i

Di dalam bab Thaharah, sebagaimana penjelasan dalam kitab-kitab fiqih lainnya, penulis memaparkan permasalahan seperti pembagian 4 wasilah thaharah (yaitu: air, tanah, batu istinja, dan najasah) dan 4 maqasidthaharah (yakni: wudhu', mandi, tayammum, dan menghilangkan najis).

Bahasan lain adalah tentang shalat (sifat shalat, rukun shalat, syarat shalat), zakat (pengertian, rukun dan syaratnya), puasa (pengertian, rukun dan syaratnya) dan haji (pengertian, rukun dan syaratnya), mu'amalah (kitab al-buyu'\}, munakahat (pernikahan), dan jinayah (pidana).

\section{Isi Naskah Al-HadiAl-Muhtajfi Syarah al-Minhaj karya Imam Abi Qasim I mam uddin Abdul Karim Ar-Rafi'i}

Naskah Al-Hadi Al-Muhtaj fi Syarah alMinhaj ini dapat dikategorikan sebagai kitab syarah. Jika diletakkan dalam kontes saat ini maka dapat dikatakan bahwa Naskah ini adalah "fiqh lengkap". Dari segi cakupan bahasannya, naskah ini secara komprehensif membahas berbagai per- soalan fiqh seperti; thaharah, shalat, zakat, puasa, haji, pernikahan, jual beli dan berbagai persoalan mu'amalah.

Naskah ini membahas berbagai persoalan. fiqh berdasarkan metode penyusunan kitab-kitab fiqh yang ada dalam mazhab syafi'i. Hal ini dapat dilihat pada susunan kitab (bab) yang dibahas di dalamnya, yaitu sebagai berikut:

1. Kitab thaharah yang mencakup; sebab-sebab hadas, wudhu', mandi, macam-macam najis, tayammum, bahasan tentang haidh,

2. Kitab shalat yang mencakup; rukun dan syarat shalat, kaifiyat shalat, waktu pelaksanaan shalat, macam-macam shalat, hal-hal yang membatalkan shalat.

3. Kitab Jana'iz yang mencakup kewajiban terhadap jenazah, tata cara penyelenggaraan jenazah, memandikan, mengkafani, menyalatkan dan menguburkan jenazah.

4. Kitab Zakat yang mencakup; rukun dan syarat zakat, muzakkki, mustahik zakat, macam-macam zakat

5. Kitab Puasa yang mencakup; rukun dan syarat puasa, waktu pelaksanaan puasa, hal-hal yang membatalkan puasa dan macam-macam puasa sunnat.

6. Kitab Haji yang mencakup: syarat-syarat haji, rukun-rukun haji, wajib-wajib haji, sunnat-sunnat haji, tata cara pelaksanaan haji, hal-hal yang diharamkan dalam ibadah haji, dan Dam (denda)

7. Kitab al-buyu' yang mencakup; rukun dan syarat jual beli, riba', macam-macam riba, macam-macam jual beli, hal-hal yang membatalkan jual-beli. Salam, Gadai, muftis (bangkrut), syirkah, wakalah, ghasb, ariyah, syuf'ah, qiradh, musaqah, ijarah, ihya' al-mawat, wakaf, luqthah, wadi'ah, fay dan ghanimah.

8. Kitab shadaqah

9. Kitab nikah yang berisi;yara 'idh, washiyat, thalaq, ruju', I'la\ zhihar, kaffarat, Wan, iddah, radha'ah, nafkah, hadhanah,

10. Kitab jarahah (qishash)

11. Kitab da'wah

12. Kitab al-bughat

Edward Heawood, op.cit h. 137 


13. Kitab riddah
14. Kitab zina
15. Kitab Qazaf
16. Kitab sirqah
17. Kitab shiyal
18. Kitab al-adhah
19. Kitab al-qadhah (peradilan)

Menurut penulis, ada beberapa hal yang menjadi perhatian terhadap isi naskah Al-Hadi Al-Muhtaj fi Syarah al-Minhaj karya Imam Abi Qasim Imamuddin Abdul KarimAr-Rafi'i di atas, yaitu sebagai berikut:

1) Di dalam kitab ini, berbagai persoalan dibahas secara detail tentang berbagai persoalan fiqh hal ini terangkum dalam sistimatika bahasan yang terdiri atas kitab, kitab terdiri atas beberapa bab dan bab terdiri dari beberapa pashal

2) Pendapat ulama hampir tidak disebutkan di dalam kitab ini.

3) Kitab ini sangat argumentatif karena naskah tersebut sangat komprehensif dan memuat alasan argumentatif baik dari Al-Qur'an dan Hadis.

\section{Corak Fiqh Naskah Al-Hadi Al-Muhtaj fi Syarah al-Minhaj karya Imam Abi Qasim Imamuddin Abdul Karim Ar-Rafi'i}

Marzuki Wah id, dalam penel itiannya tentang fiqh di Indonesia. Sejak abad ke-17 sampai abad 20, menyatakan bahwa dinamika fiqh Indonesia abad ke17 dan 18 adalah dalam wacana Syafi'iyah. Marzuki Wahid mengemukakan 2 alasan. Pertama, proses Islamisasi di Indonesia sejak abad ke-12 dan ke-13 merupakan saat-saat di mana perkembangan hukum Islam berada dalam masa krisis dengan penutupan pintu ijtihad sebagai titik terendahnya, walaupun pada fase berikutnya banyak tokoh yang menggugat hal tersebut. Para ahli tidak lagi berani berpikir sebebas dan sekreatif mungkin, tetapi lebih disibukkan oleh berbagai aktivitas pemikiran untuk mendukung mazhabnya masing-masing. Kedua secara kebetulan para "aktifis" yag melancarkan proses islamisasi di Indonesia sebagaimana disinyalir oleh para sejarawan, adalah mereka yang bermazhab Syafi'i, walaupun pada perkembangan berikutnya tidak semua umat Islam Indonesia menyandarkan perilaku keagamaannya pada kerangka pemikiran fiqh Imam Asy-Syafi'i, terutama pada awal abad ke 20 ketika gerakan pembaharuan menemukan momentumnya. ${ }^{12}$

Pendapat Marzuki Wahid di atas, sejalan dengan penuturan DR. Subhi Mahmassani dalam bukunya The Philosophy of Jurisprudence in Islam. Ia menulis bahwa negara Indonesia, mayoritas penduduknya menganut mazhab Syafi'i. ${ }^{13}$

Perkembangan fiqh secara umum di atas, tentu saja tidak jauh berbeda dengan perkembangan fiqh yang ada di Aceh pada masa lampau (dalam konteks Aceh ketika masih dalam bentuk kerajaan). Hal ini dapat dilihat pada tokoh-tokoh fiqh ketika Aceh masih dalam bentuk kerajaan. Seperti; Nur Al-Din Al-Raniry (W. $1068 \mathrm{H} / 1658 \mathrm{M})^{14}$ dan Syeikh Abdurrauf Singkel $(1024 \mathrm{H} / 1615 \mathrm{M})^{15}$ merupakan icon ulama saat itu yang merupakan penganut mazhab syafi'i.

Meskipun Al-Raniry merupakan tokoh yang lebih dikenal sebagai seorang sufi, akan tetapi ia juga merupakan salah seorangjuqahd' yang memiliki peran dalam perkembangan fiqh di Aceh. Hal ini dapat dilihat pada fakta bahwa Al-Raniryjuga menulis Kitab-kitab di bidang figh. Salah satu karya monumentalnya adalah Shiratal Mustaqim. Kitab ini ditulis dalam bahasa Melayu yang sampai sekarang terus dibaca di Aceh dan beberapa daerah di Indonesia ${ }^{16}$.

Abdurrauf memiliki sekitar 21 karya tulis yang terdiri dari, kitab tafsir, kitab hadis, kitab fiqh dan kitab tasawuf. Meskipun Abdurrauf lebih dikenal

"2 Marzuki Wahid dan Rumadi. 2001. Fiqh Mazhab Negara: Kritik atas Politik Hukum Islam di Indonesia. Yogyakarta: LKIS. h. 114-115.

" Tulisan Subhi Mahmassani ini di muat dalam Ali Yafie. 1997. Teologi Sosial: Telaah Kritis Persoalan Agama dan Kemanusiaan, Cet. I; Yogyakarta: LKPSM. h. 133.

"Nur Al-Din Al-Raniry dilahirkan di Ranir (Randir), sebuah kota pelabuhan tua di pantai Gujarat. Tahun kelahirannya tidak diketahui, akan tetapi diduga kuat ia lahir menjelang akhir abad keenan belas. Ibunya adalah seorang Melayu sedang ayahnya adalah seorang Hadhrami. Azyumardi Azra, Jaringan Ulama Timur Tengan dan Kepulauan Nusantara Abad XVII dan XVIII, (Cet. IV; Bandung: Mizan, 1998 ), h. 169.

Abdurrauf lahir di Aceh tahun $(1024 \mathrm{H} / 1615 \mathrm{M})$ nama aslinya adalah Aminuddin Abdurrauf bin Ali al-Jawi al-Fansuri al-Singkili. Abdurrauf Singkel merupakan sosok pemikir dan ulama terkemuka, ia telah melahirkan karya-karya dalam berbagai disiplin ilmu keislaman (islamic studies) yang merupakan kekayaan intelektual muslim Indonesia yang sangat berharga. Abdul Aziz Dahlan, et.al. Ensiklopedi Hukum Islam. Jilid 1 Jakarta: Ikhtiar Baru Van Hoeve, 1996), h. 5.

${ }^{16}$ Van Brinessen, Martin. 1999. Kitab Kuning. Pesantren dan Tarekat. Bandung: Mizan. h. 113 
sebagai tokoh sufi terkemuka di Nusantara, tapi ia juga merupakan mujtahid/fuqahd' yang handal. Karyanya di bidangfiqhyang sangat terkenal adalah kitab Mir 'at -il-Thullab Fi Tafshil Ma'rifatil Ahkam al-Syar 'iyyah U Malikil Wahhab. Kitab ini merupakan kitab fiqh yang ditulis atas permintaan dari Sulthanah Safiatuddin >ebagai panduan bagi para Qadhil'

Jika dihubungkan dengan" naskah corak fiqh naskah Al-Hadi Al-Muhtaj fi Syarah al-Minhaj, maka keberadaan naskah ini dapat dijadikan sebagai salah satu data pendukung untuk memperkuat berbagai «.esimpulan bahwa fiqh yang menjadi mainstream pada masa kerajaan di nusantara, termasuk Aceh adalah fiqh yang bermazhab Syafi'i.

Dalam penelusuran penulis atas naskah Al-Hadi Al-Muhtaj fi Syarah al-Minhaj ini, penulis menemukan bahwa pengarang sendiri menegaskan/ "nembatasi diri bahwa kitab tersebut didasarkan pada Tiazhab Imam Syafi'i dan para pengikutnya."

Dalam penelusuran lebih lanjut penulis menemukan bahwa pengarang naskah di atas, Imam Abi > asim Imamuddin Abdul Karim Ar-Rafi'i, merupakan ruqaha' yang menganut mazhab Syafi'i yang wafat pada tahun $623 \mathrm{H}^{19}$

Dengan berbagai alur pikir di atas, maka dapat asimpulkan bahwa naskah Al-Hadi Al-Muhtaj fi varah al-Minhaj dapat dijadikan sebagai salah satu bukti pendukung bahwa corak fiqh yang berkembang atau dianut masyarakat Aceh pada zaman kerajaan adalah fiqh bermazhab syafi'i.

\section{PENUTUP}

\section{Kesimpulan}

Dari pembahasan yang telah dikemukakan di atas, maka dapat ditarik beberapa kesimpulan sebagai ^erikut:

Naskah yang berjudul Al-Hadi Al-Muhtaj $f i$ arah al-Minhaj merupakan hasil karya dari Imam Abi Qasim Imamuddin Abdul Karim ArRafi'i. Naskah ini menggunakan bahasa Arab aengan aksara Arab yang berbentuk prosa. Kondisi naskah secara umum baik dan isi teks dapat dibaca dengan baik. Hanya saja pada pertengahan naskah dimakan tinta. Kondisi fisik naskah dapat digambarkan bahwajilidan naskah masih asli yang terbuat dari kulit binatang berwarna coklat. Bahan naskah ini adalah kertas Eropa. Ukuran kertasnya adalah 22 x $16 \mathrm{~cm}$ sedangkan ukuran teksnya 15 x $10 \mathrm{~cm}$. Tentang cap kertas ditemukan watermark yang bergambar bulan sabit bersusun tiga (Edward Heawood, no. 863). Diperkirakan sekitar tahun 1610 M. Dari bentuk kertasnya pun dapat dipastikan bahwa naskah menggunakan kertas Eropa. Naskah ini berjumlah 420 halaman. Halaman yang kosong berjumlah 16 halaman (2 halaman di awal naskah, 11 halaman di tengah dan 3 halaman di akhir naskah). Jenis khat yang digunakan adalah khat naskhi dengan menggunakan tinta hitam serta rubrikasi menggunakan tinta merah. Pada catchword naskah ditemukan bahwa di setiap halaman terdapat alihan.

Naskah Al-Hadi Al-Muhtaj fi Syarah alMinhaj ini berisi kajian fiqh yang sangat komprehensif tentang berbagai persoalan hukum fiqh. Dalam peta kajian fiqh nusantara, kitab naskah Al-Hadi Al-Muhtaj fi Syarah al-Minhaj ini semakin memperteguh kenyataan bahwa corak fiqh yang berkembang di Aceh pada masa kerajaan adalah fiqh mazhab Syafi'i.

\section{Rekomendasi}

Perlu upaya lebih lanjut untuk meneliti naskahnaskah fiqh dalam bentuk manuskript agar khazanah manuskript Aceh terpelihara terutama naskah yang masih ada dalam masyarakat.

Untuk mengetahui lebih lanjut tentang mainstream fiqh yang berkembang pada masa kerajaaan Aceh, maka kajian atas naskah-naskah kuno Aceh hams digalakkan.

\section{Ucapan Terima Kasih}

Penelitian ini telah dapat diselesaikan dengan baik, sesuai dengan prosedur penelitian ilmiah. Penulis menyadari sepenuhnya bahwa dalam penyelesaian penelitian ini tentunya tidak terlepas dari dukungan dan bantuan dari berbagai pihak. Olehnya itu, penulis menyampaikan penghargaan dan ucapan terimah kasih yang setulus-tulusnya, kepada beberapa

Hamid, Salahuddin dan Iskandar Ahza. 2003. 100 Tokoh Islam yang Paling Berpengaruh di Indonesia. Cet. I; Jakarta: PT. Intimedia ?:pta Nusantara. h. 203.

"Imam Abi Qasim Imamuddin Abdul Karim Ar-Rafi'i, Tth. Al-Hadi Al-Muhtaj fi Syarah al-Minhaj. h. 8.

" CD Room, Maktabah Al-Syamilah. 
pihak. Pertama, kepada Rektor IAIN Ar-Raniry, Bapak Prof.DR. Farid Wajdy, MA dan Dekan Fakultas Syari'ah IAIN Ar-Raniry, Bapak DR. Nazaruddin A. Wahid karenatelah memberi izin untuk mengikuti Pendidikan dan Pelatihan (Diklat) Penelitian Naskah Keagamaan Kementrian Agama di Jakarta yang outputnya penulis mendapatkan kesempatan untuk melakukan penelitian ini. Kedua, kepada Kepala Puslitbang Lektur Keagamaan RI Jakarta, Bapak Prof. DR. Maidar Harun yang telah memberikan bantuan dana untuk penelitian ini. Ketiga, kepada Dewan Redaktur Jurnal Litbang Kementrian Agama Makassar yang berkenan menerbitkan hasil penelitian ini.

\section{DAFTAR PUSTAKA}

CD Room Maktabah Syamilah

Depag RI. 2003. Pedoman Penulisan dan Pentashihan Buku Keagamaan, Jakarta: Badan Litbang Agama dan Diklat Keagamaan.

Hamid, Salahuddin, dan Iskandar Ahza. 2003. 100 Tokoh Islam yang Paling Berpengaruh di Indonesia. Cet. I; Jakarta: PT. Intimedia Cipta Nusantara.

Ibrahim, Muslim, dalam Husni Rahiem (Ed). 1991. Perkembangan Ilmu Fiqh di Dunia Islam. Cet. 2; Jakarta: Bumi Aksara.

Jatnika, Rakhmat. 1991 Perkembangan Ilmu Figh di Dunia Islam, dalam Husni Rahiem (Ed) Perkembangan Ilmu Fiqh di Dunia Islam. Cet. 2; Jakarta: Bumi Aksara.

Manaf, Moenir. 1998. Petunjuk Bimbingan Manasik Haji dan Umrah, Cet. VIII; Jakarta; PT Hidhakarya Agung.

Mu'jizah. 2005. Martabat Tujuh: Edisi Teles dan Pemaknaan Tanda serta Simbol, Jakarta: Djambatan.

Pudjiastuti. 2006. Titik, Naskah dan Studi Naskah, Cet. I; Bogor: Akademia.

Qardhavvi. 1993. Yusuf, Madkhal li Dirdsat al-Syari'at alIslamiyah, Cet. I; Beirut: Muassasat al-Risalah.

Sirry, Mun'im A. 1996. Sejarah Fiqh i Islam: Sebuah Pengantar. Cet. II; Surabaya: Risalah Gusti.

Wahid, Marzuki, dan Rumadi. 2001. Figh Mazhab Negara: Kritik atas Politik Hukum Islam di Indonesia, Cet. I; Yogyakarta: LKIS.

Yafie. Ali. 1997. Teologi Sosial: Telaah Kritis Persoalan Agama dan Kemanusiaan, Cet. I; Yogyakarta: LKPSM. 